I Universidade Federal do Rio de Janeiro (UFRJ), Departamento de Sociologia, Rio de Janeiro, RJ, Brasil andrebotelho@digirotas.com.br

II Universidade Federal do Rio de Janeiro (UFRJ), Departamento de Sociologia, Rio de Janeiro, RJ, Brasil antoniobrasiljr@gmail.com

\title{
FLORESTAN FERNANDES ENTRE DOIS MUNDOS: ENTREVISTA COM ELIDE RUGAI BASTOS, GABRIEL COHN E MARIZA PEIRANO
}

Este é o primeiro dossiê de Sociologia \& Antropologia sobre um autor brasileiro. A escolha de Florestan Fernandes poderia parecer natural pelo lugar que ele ocupa na formação das ciências sociais no país e pela convicção, quase generalizada entre nós, de que se trata de um autor "clássico". É justamente essa naturalização do lugar e do estatuto da obra de Florestan Fernandes, porém, que gos taríamos de problematizar e colocar em tensão com este dossiê. Reputamos que suas contribuições podem - e devem - ser testadas à luz dos problemas teóricos, metodológicos e empíricos sobre os quais se vêm debruçando as ciências sociais hoje, procedimento que permite simultaneamente "deslocalizar" sua obra para além de seus contextos imediatos de produção e trazer novos ângulos de observação de suas relações com esses mesmos (e outros) contextos. Durante muitos anos o interesse manifestado pelas ciências sociais brasileiras sobre Florestan Fernandes esteve, em grande medida, relacionado diretamente ao seu papel como ator central da institucionalização das ciências sociais na Universidade de São Paulo. Posição compreensível em vários níveis. A começar pelo fato de que entender a institucionalização das ciências sociais no Brasil no contexto de sua plena consolidação e grande dinamização nas duas últimas décadas do século passado parece ter constituído uma condição de inteligibilidade do próprio ofício de cientista social entre nós, esclarecendo o processo mais amplo e às vezes ambíguo em que ele se encontrava. Assim, a construção dos cursos, a imposição de um padrão científico universal ao trabalho acadêmico, a importação, aclimatação e tradução de recursos cognitivos a uma realidade social historicamente tão distinta da europeia que forjou essas disciplinas são temas 
inescapáveis da reflexão sobre as ciências sociais no Brasil. E são temas que contam já com uma longa história consolidada e também consagrada nas ciências sociais brasileiras. É certo que muitos deles começam a ganhar hoje novos interesses, como a questão da importação das ciências sociais, que passa a ser vista, também, em relação aos debates sobre eurocentrismo, pós-colonialismo e teorias Sul-Sul, por exemplo. ${ }^{\text {I }}$

Procurando tirar consequências do já realizado, a aproximação a Florestan Fernandes como um autor clássico das ciências sociais que propomos neste dossiê é de outra ordem. Uma das melhores definições de "clássico" talvez seja mesmo a conhecida de Ítalo Calvino (2004), a de que clássico é aquele autor ou livro "que nunca terminou de dizer aquilo que tinha para dizer". Movimento constitutivo das ciências sociais, que implica não uma, mas muitas histórias intelectuais que afetam sua prática cotidiana, voltar aos seus autores clássicos é sempre uma redescoberta. Na releitura, de fato, sempre podemos surpreender algo que o clássico já estava dizendo, mas que nós, de alguma forma, não dispúnhamos então dos recursos necessários para entender plenamente.

Obviamente, isso não significa dizer que o clássico esteja, necessariamente, à frente de seu tempo; afinal, ao menos do ponto de vista sociológico, nenhum autor está exatamente fora de seu tempo e contexto social. Em lugar disso, são as dinâmicas da recepção das obras que nos ajudam a compreender por que certos temas ou problemas de uma mesma obra (ou de um mesmo tempo) são privilegiados (em detrimento de outros) num contexto e não noutro (Villas Bôas, 2006). Uma obra, por mais inovadora que seja, nunca é lida num vazio de expectativas e de relações. Não constitui uma fragilidade, mas antes uma das forças dos clássicos, o fato de eles terem elaborado suas ideias por meio da reflexão sobre os problemas substantivos de sua época. As próprias interpretações desses fenômenos, porém, compreendem necessariamente dimensões analíticas - teóricas e também metodológicas -, que perfazem a gramática básica da disciplina (no caso as ciências sociais) e são recorrentemente retomadas como recursos intelectuais para a interpretação de novos e também velhos fenômenos da vida social.

Como já observado justamente em relação a Florestan Fernandes (Brasil Jr. \& Botelho, 20I7), duas posições básicas parecem conviver e disputar o sentido dessa aproximação entre passado e presente que a releitura de um clássico implica - aproximação metateórica tão mais instigante porque cheia de riscos que desafiam a especialização rotinizada na prática cotidiana das nossas disciplinas. De um lado, há visões mais ou menos românticas sobre os pioneiros das ciências sociais que destacam sua genialidade autoral ou o aparato cognitivo de suas interpretações, considerado mais potente justamente porque anterior ao processo de extrema especialização do conhecimento assumido também por nossas disciplinas. De outro, visões que enfatizam, antes, a continuidade na própria história da sociedade brasileira, uma história reiterativa, uma moderni- 
zação conservadora em que, malgrado as mudanças ocorridas nas últimas décadas, a ruptura substantiva com o passado parece sempre postergada. Autores do passado, nessa segunda perspectiva, acabam se tornando nossos contemporâneos pela persistência de estruturas de desigualdades sociais e políticas, pois os processos sobre os quais teorizaram ainda nos diriam respeito substantivamente. Entendemos que, mais do que uma resposta unívoca, tais questões configuram um campo problemático de pesquisa em cujo centro se coloca a noção de processo social e histórico, crucial para ambas as posições. Embora não se trate exatamente de se fazer, aqui, a defesa das visões diacrônicas nas ciências sociais, a provocação de Norbert Elias (1987) em relação à tendência atual do sociólogo a se refugiar no presente não deixa mesmo de ser pertinente.

De acordo com o título da entrevista que começamos a realizar em outubro de 2016 com Elide Rugai Bastos, Gabriel Cohn e Mariza Peirano durante o 40 Encontro Anual da Anpocs, em Caxambu, e aqui publicada, interessa-nos inquirir o significado da produção de Florestan Fernandes entre dois mundos, entre o legado de sua atuação no passado de nossas ciências sociais e os desafios que ela nos coloca no presente. A ênfase no "entre" não é aleatória, pois revela um modo de se relacionar com universos distintos que não opera com disjuntivas - e nem com uma perspectiva de superação linear -, mas que faz das interações entre esses universos, e do conflito potencial que trazem, o cerne do problema.

Esse modo de operar, aliás, não escapava ao próprio Florestan, que analisou a formação da sociedade brasileira como o encontro reiterado (mas dinâmico e sempre diverso) do arcaísmo com a modernidade. E que, por isso mesmo, entendia que a atuação do cientista social no Brasil deveria operar num duplo registro, o da contribuição ao desenvolvimento da ciência e o da responsabilidade pública do intelectual - mundos sem dúvida distintos e em redefinição constante, o da ciência e o da cidadania, mas que se deveriam dinamizar mutuamente. Mais uma vez, o que importa é a relação que aproxima e também distancia, que liga e também aparta. Vale registrar ainda que Florestan também trabalhou entre a antropologia e a sociologia, não apenas porque deixou obras clássicas nas duas disciplinas, como A função social da guerra na sociedade tupinambá (I952) e A revolução burguesa no Brasil (I975), por exemplo, mas porque esse trânsito ajuda a explicar como foi possível a pesquisa inovadora e original que resultou em A integração do negro na sociedade de classes (I965), que combina análise histórica e trabalho de campo, enfoque macrossociológico e atenção fina à modelagem das personalidades dos atores sociais, rigor teórico-metodológico e incorporação crítica das explicações "nativas" dos colaboradores-informantes da população negra de São Paulo.

Nossa proposta de leitura é testada, portanto, com alguns dos principais estudiosos da obra de Florestan Fernandes. Gabriel Cohn, professor emérito da Faculdade de Filosofia e Ciências Humanas da Universidade de São Paulo (FFL- 
$\mathrm{CH} / \mathrm{USP}$ ), produziu reflexões seminais sobre o esquema teórico-metodológico - baseado num ecletismo bem temperado e na rotação de perspectivas - e as chaves analíticas - sintetizadas nas ideias de padrões e dilemas - que articulam o que ele denomina perspectiva plebeia radical daquele sociólogo. Elide Rugai Bastos, professora titular da Universidade Estadual de Campinas (Unicamp), discutiu pioneiramente a visão sociológica de Florestan Fernandes sobre a questão racial que levou ao questionamento do mito da democracia racial, e é autora de estudos clássicos sobre a chamada escola sociológica paulista, na qual identifica as razões e os efeitos do atraso do país como eixo de reflexão e a perspectiva da periferia como padrão teórico-metodológico. Por sua vez, Mariza Peirano, professora titular aposentada da Universidade de Brasília, onde ainda atua como pesquisadora no Departamento de Antropologia, produziu análise igualmente pioneira e até hoje sem paralelo dos trabalhos antropológicos de Florestan Fernandes sobre os Tupinambá. ${ }^{2}$

Além da entrevista, este dossiê abriga mais três artigos, que procuram ampliar a agenda de pesquisas a ela referida. Maria Arminda do Nascimento Arruda, também destacada analista da obra do sociólogo paulista, retoma a fortuna do autor para se lançar a novas hipóteses sobre a atualidade de Florestan Fernandes, como indica o título escolhido para seu artigo. Enfatizando as dimensões culturais de sua produção sociológica, a autora explora o potencial analítico da contribuição de Florestan Fernandes ao entendimento dos impasses recorrentes da formação histórica particular da sociedade moderna no Brasil à luz de sua crise contemporânea. Assim, aponta o descompasso entre a cultura política das nossas classes dirigentes, refratárias a demandas sociais de caráter democrático e civilizatório, e a dinâmica resultante da recente incorporação social e educacional de camadas subalternas. Situando ainda a obra de Florestan em relação ao chamado paradigma da formação, a autora acompanha seu percurso do gênero monográfico ao ensaístico a fim de mostrar que ela transita da aposta na possibilidade de construção de uma sociedade moderna nos trópicos, passando pela percepção das distorções da aclimatação entre nós desses valores modernos, até a afirmação da falência do projeto civilizatório brasileiro em A revolução burguesa no Brasil.

Alejandro Blanco e Antonio Brasil Jr., em "A circulação internacional de Florestan Fernandes", analisam a produção e a atuação de Florestan fora do Brasil, confrontando-as com o tipo de circulação internacional realizado por seus contemporâneos latino-americanos. Ao localizar seus livros e capítulos de livro publicados no exterior, as resenhas dedicadas a sua obra em periódicos estrangeiros, bem como sua vinculação a instituições de ensino e pesquisa de outros países, os autores relacionam sua tardia circulação internacional, basicamente concentrada na América do Norte - sobretudo nos Estados Unidos e, em menor medida, no México, ao contrário de seus contemporâneos, que se voltaram precocemente para os países da América do Sul -, a determinadas particularidades 
das ciências sociais em São Paulo. Esse artigo ainda nos ajuda a perceber como a obra de Florestan foi gestada entre dois mundos só à primeira vista apartados - o de seu grupo na cadeira de sociologia I da Universidade de São Paulo e o das ciências sociais cada vez mais internacionalizadas a partir de meados do século passado -, bem como o modo muito próprio como Florestan avaliava as conexões entre localismo e cosmopolitismo nas práticas científicas de então.

Mário Augusto Medeiros da Silva, em "Órbitas sincrônicas: sociólogos e intelectuais negros em São Paulo, anos I950-I970", investiga as relações entre cientistas sociais e intelectuais e ativistas negros em São Paulo antes e depois do golpe civil-militar de I964, perscrutando como se formou um horizonte compartilhado de problemas (de pesquisa e de luta política) em torno de um projeto de mudança social pautado pela luta antirracista. $O$ autor mostra que esse compartilhamento - cujo ponto focal é Florestan Fernandes - não envolveu só consenso e aliança, mas também tensões e conflitos. $O$ artigo ressalta como as aproximações entre pesquisa científica e movimentos sociais constituem uma via de mão dupla e que a análise deve, por isso mesmo, restituir os termos dessa relação sem perder de vista suas especificidades, isto é, sem confundir os sentidos diversos, ainda que entrelaçados, que cientistas sociais e ativistas atribuem a essas conexões. A análise do caso de Eduardo de Oliveira e Oliveira, sociólogo negro formado na USP e importante ativista do movimento negro paulistano durante o regime militar, é ilustrativa desse procedimento.

Na seção Registro de Pesquisa, o leitor encontrará uma das primeiras resenhas publicadas sobre A revolução burguesa no Brasil (I975), escrita por Silviano Santiago a convite do próprio Florestan Fernandes, que rememora aquela circunstância e suas relações com o sociólogo paulista nos Estados Unidos e posteriormente, quando ambos estavam de volta ao Brasil. A resenha de Silviano é um ótimo exemplo, ademais, de como um mesmo contexto intelectual envolve posições tão diferentes, oferecendo recursos e protocolos de leitura distintos dos consagrados no interior de uma disciplina que, sem dúvida, valem a pena ser explorados contemporaneamente. Não será mero acaso ainda que Silviano Santiago (1973) seja o autor do conceito de "entre-lugar" que, embora originalmente relacionado à literatura de ficção latino-americana, talvez, possa nos ajudar justamente a desnaturalizar os lugares de Florestan Fernandes sedimentados pelo tempo e pela rotina acadêmica.

É assim, entre mundos diferentes - passado e presente, sociologia e antropologia, Brasil e o contexto internacional, história e teoria, academia e movimentos sociais, entre outros -, que propomos revisitar Florestan Fernandes com este dossiê. Mobilizando perspectivas e debates mais plurais, apostamos no interesse renovado, particularmente teórico, de sua contribuição às ciências sociais, bem como na capacidade e na qualidade de sua interpelação ética e política à sociedade contemporânea. Voltar aos clássicos do ponto de vista aqui proposto ${ }^{3}$ nos lembra, ademais, de que nunca partimos do zero para formular 
novos problemas e novos conceitos suscitados no fluxo opaco da vida social, o que não deixa de corroborar o caráter paradoxal da ideia de uma perpétua "imaturidade" - ou o "dom da eterna juventude" - das ciências sociais, de que já falava Max Weber. Como sabia o próprio Florestan Fernandes, que já em Fundamentos empíricos da explicação sociológica (I953) o demonstra cabalmente, os clássicos são recursos intelectuais dos quais não podemos abrir mão, pois nos ajudam a revelar os vários lados deste objeto prismático por excelência que é a vida social.

Sociologia \& Antropologia. Gostaríamos de começar perguntando como Florestan Fernandes aparece na trajetória acadêmica e intelectual de vocês.

Elide Rugai Bastos. Gabriel, que foi o primeiro a ter contato com o professor Florestan, poderá responder primeiro.

Gabriel Cohn. De fato, meu contato se deu cronologicamente primeiro, pela USP. Mas o contato realmente intenso, de convivência intelectual, foi muito mais da Elide. No meu caso, embora existisse o contato enquanto ele estava na USP, não teve a intensidade que se poderia imaginar. Pode parecer estranho, mas eu nunca tive a oportunidade de assistir a um curso de Florestan; nosso contato era mais informal. Tivemos uma aproximação mais forte quando ele já estava fora da universidade, aposentado, nos anos finais da vida; ainda assim, acabou se dando muito mais pelo fato de eu escrever sobre ele, perguntar-lhe coisas, ouvi-lo. Para citar um pouco o "jeitão" Florestan: estou eu andando na famosa rua Maria Antônia com um livro de teoria sociológica debaixo do braço que tinha que levar para a biblioteca da Economia - que era muito melhor do que a nossa -, quando o ouço perguntar-me (como sempre fazia): "que livro é esse que você está lendo?". Ao lhe mostrar, ele me diz daquele jeito dele, despachado: "Bom livro, mas eu já estava dizendo isso I5 anos atrás". Trata-se, portanto, de um contato mais intelectual - de interesse pela obra -, do que de real impregnação pela presença dele, o que acabou ocorrendo indiretamente por artigos de alunos deles, os meus mestres. E ele foi fundamental nisso. No curso de Ciências Sociais da USP, Florestan estava sendo deixado de lado e esquecido; Brasílio Sallum Jr., porém, nunca deixou de insistir, em suas atividades, na importância da obra de Florestan e teve o grande mérito de o manter vivo na instituição.

E.R.B. Meu contato com a bibliografia de Florestan foi muito anterior ao contato pessoal, que ocorreu na PUC-SP, quando, depois da aposentadoria e de ter voltado do exterior, ele foi convidado a trabalhar no Departamento de Política. Nessa época, eu já era professora da PUC e estava iniciando meu doutorado. Eu o conheci como aluna, quando frequentei um curso brilhante que ele ofereceu. Antes disso, porém, uma vez fui à sala dos professores procurar a professora Carmen Junqueira e encontrei Florestan, que me convidou a sentar-me. Eu trazia comigo o livro La experiencia del movimiento obrero, de I974, e ele indagou: "que 
livro é esse? Não conheço, é novidade?". Respondi com toda timidez diante do "mito", que ele já era: "Não é novidade; Castoriadis reuniu uma série de trabalhos já publicados por Socialismo ou Barbárie e escreveu uma introdução." Perguntou se a introdução era boa, e eu disse que não concordava com ela, porque Castoriadis afirmava não haver, no marxismo, historiadores do movimento operário, ignorando Thompson, que cita apenas de passagem; e, além disso, considerava equivocada sua explicação de como construir uma análise dialética. Ele falou: "ah, sei bem". Carmen chegou, e a conversa ficou por aí. Na semana seguinte, fui assistir a uma aula, ele estava na porta da sala de pós-graduação e disse: "vem cá que quero conversar com você. Eu peguei o livro Experiência do movimento operário e você tem razão. Mas é isto, isto e aquilo". Explicou bem minha dúvida sobre dialética e em que o Castoriadis estaria equivocado. Em seguida me perguntou o que eu fazia e por que estava lendo esse livro. Eu contei que dava aula, e que ensinava sobre movimentos sociais no curso de ciências sociais.

Ele então me aconselhou a escrever todas as minhas aulas, porque ao final do curso teria um livro pronto. Pobre de mim, não é? Segui o conselho, e escrevi alguns artigos sobre movimentos sociais e sobre Alain Touraine.

S\&A. Você está falando de quando exatamente, Elide?

E.R.B. Estou me referindo ao início dos anos 8o. Ele me perguntou ainda o que eu pesquisava para a tese de doutorado. Quando eu lhe contei que queria comparar duas interpretações sobre o Nordeste, as de Euclides da Cunha e Gilberto Freyre, ele disse: "Você enlouqueceu. São dois contextos totalmente diversos. Escolha o Gilberto Freyre porque ele é mais importante para entender o Brasil de hoje". Como já havia tido essa sugestão de Octavio Ianni, meu orientador, decidi segui-la. E Florestan sempre me perguntava simpaticamente a respeito do desenvolvimento do trabalho, de modo que me senti absolutamente à vontade para convidá-lo a integrar o comitê de mudanças do curso de Ciências Sociais, que eu dirigia na faculdade. Ele participou do comitê, mas num determinado momento disse: "a universidade não tem mais apelo para mim, e a universidade que eu imaginei que pudesse ser construída já está destruída”.

Ele parecia estar extremamente deprimido com o rumo que ela estava tomando. Nós sempre conversávamos, tomando cafezinho, e ele me ajudou bastante não só na formação dos cursos como na escritura da tese. Eu não conheci aquele Florestan bravíssimo.

G.C. Florestan era, pelo menos na época em que o conheci, um homem profundamente doce, até tímido, com alta carência afetiva. Não tinha nada nele daquela figura que entrava batendo o pé na porta. Ele fazia isso porque tinha que fazer, estava desempenhando seu papel, digamos. Pessoalmente era muito gentil.

S\&A. E como se deu o envolvimento de vocês com a obra do Florestan? Como foi a experiência com o autor Florestan Fernandes? 
G.C. Nas Ciências Sociais, que eu estava fazendo, havia um forte pendor, sobretudo por parte de alguns professores, a insistir na leitura dos grandes trabalhos brasileiros, de modo que Florestan não poderia estar ausente. A figura mais importante nesse estímulo - que já virou chavão meu citar, mas o farei mais uma vez - era Octavio Ianni, porque ele nos obrigava a ler todas as tendências possíveis, e não perdoava. (A direita da USP, que o aposentou, alegava que ele e seus colegas também atingidos faziam doutrinação em sala de aula. Justo eles, com sua ética profissional impecável). Mas era Florestan que acabava tendo um papel forte, embora não fosse um protagonismo tão marcado. Ele era um autor que precisávamos conhecer. Todos o respeitavam muitíssimo; Florestan já era autor de obra notável.

À ideia de que, como escreveu Olavo de Carvalho, Florestan não passava de um funcionário público, tive a chance de responder que ele teria orgulho de assim ser chamado. E eu testemunhei o mesmo orgulho em Jesus Soares Pereira, um dos artífices dos grandes projetos da Era Vargas, como a Companhia Siderúrgica Nacional e a Petrobras, que morava numa casa modesta na Tijuca. Dá tristeza ver que esse orgulho de ser servidor público, que aquela geração possuía, não existe mais no nosso país. Florestan o tinha. Isso estava presente em sua postura, no que ele falava, no modo de se colocar. Isso se via até no famoso guarda-pó que sempre usava e que até virou motivo de piadas. Nunca foi de grandes gestos, de vozeirão, mas tinha uma presença que se impunha. Essa é uma lição que aprendemos com esses mestres, que tinham profundo respeito pelos seus alunos. Os papéis não se confundiam, mas havia respeito mútuo, e as instituições estavam vivas. Era a atmosfera que respirávamos. Alguns anos atrás presenciei pequeno incidente em reunião da Anpocs que me deixou chocado e que nunca ocorreria naquele ambiente. Entra numa das salas de eventos uma figura importante da Anpocs, ex-presidente, e um jovem estudante que trabalhava no congresso lhe pede timidamente que coloque o crachá, por ser de uso obrigatório. O homem então passou uma ralhada no estudante, no estilo "você sabe com quem está falando?". Florestan jamais faria algo semelhante. Quando as instituições são realmente vigorosas, ninguém precisa levantar a voz. E Florestan era muito importante no cultivo dessa atmosfera, não só por sua palavra, por sua voz e pelo que passava nos seus escritos, mas por sua conduta.

E.R.B. Meu contato com a obra dele é anterior ao conhecimento pessoal. Eu pretendia fazer mestrado em sociologia, mas, como havia feito filosofia, pensava: "não vou pôr o pé na faculdade, porque todo mundo ali leu Durkheim, Weber e Marx inteiros e eu vou passar mal". Então, antes de ler, precisava de uma orientação, pois o faria sozinha, e peguei Fundamentos empíricos para ter um roteiro. Nesse momento tive a sensação de que eu não entenderia nada. Então conversei com minha irmã, Ildes Rugai, que era aluna da Faculdade de 
Ciências Sociais, e ela recomendou que lesse diretamente os autores, pois assim entenderia melhor. Muito mais tarde, depois de tê-los lido, voltei ao livro e me dei conta de que não se tratava de um desenvolvimento sobre os autores, mas de anotações de aula. O único texto que tem um desenvolvimento, e que era justamente o que eu tinha entendido, era aquele sobre funcionalismo.

Ali eu me aproximei do Florestan autor e percebi sua genialidade. Em Fundamentos empíricos ele mostra aqueles pontos que temos que entender nos autores. Quando fui fazer o projeto de pesquisa do mestrado li o texto em que Florestan fez um levantamento das fontes para os estudos sobre os Tupinambá. ${ }^{4}$ E, desde então, a todos os meus orientandos digo que devem fazer um balanço crítico da bibliografia naqueles moldes. Senão é difícil provar a originalidade da sua abordagem. E isso graças a esse Florestan, que normalmente se lê depois ou não se lê, porque o texto é do período em que ele estudava na Escola de Sociologia e Política, fazendo a pesquisa na área de antropologia. Foi um dos primeiros textos que li depois de Fundamentos empíricos. Acho um texto notável.

Mariza Peirano. Minha experiência com Florestan Fernandes foi bem diferente das que Elide e Gabriel tiveram. Li muito sua obra, mas a única vez que nos encontramos foi no dia Io de dezembro de I978, por duas horas, em sua casa na rua Nebraska. Em I978 eu havia chegado dos Estados Unidos, onde fazia meu doutorado, para entrevistar alguns cientistas sociais com o objetivo de esclarecer alguns pontos que me instigavam quanto ao desenvolvimento da antropologia no Brasil. Havia lido intensa e extensamente as obras de muitos cientistas sociais como preparação para as conversas que teria com Florestan, Darcy Ribeiro, Antonio Candido, Roberto Cardoso de Oliveira, Luiz de Castro Faria. ${ }^{5}$ Para entender o desenvolvimento da antropologia, em especial a que se fazia naquele momento, certamente era preciso começar pela sociologia dos anos I950. Assim, escrevi para Florestan, que aceitou conversar comigo.

Como não convivi com ele, não tenho histórias do dia a dia para contar. Cursei ciências sociais no Rio de Janeiro, de I966 a I970, depois de abandonar o curso de arquitetura na UnB no final de I964. Como meus créditos em arquitetura não foram reconhecidos nem em Recife, em I964, nem no Rio, em I965, precisei mudar de área. A escolha das ciências sociais em um novo vestibular no Rio não foi opção difícil porque, na UnB, eu havia feito cursos nas Ciências Sociais, paralelos aos da Arquitetura, com Albertino Rodrigues, Perseu Abramo e José César Gnaccarini.

Hoje, posso distinguir a influência de Florestan em quatro momentos: na graduação que fiz na Faculdade Nacional de Filosofia (FNFi) e IFCS/UFRJ, onde aguardávamos, ansiosamente, as publicações de Florestan e de todos aqueles que considerávamos parte da chamada escola paulista de sociologia. São Paulo era a referência. Como a graduação era precária naquela época, res tava-nos um certo autodidatismo, e formávamos grupos de estudo para debater 
epistemólogos (Bachelard, Canguillem) e autores principalmente marxistas (Althusser, Poulantzas), articulando-os com autores brasileiros. O segundo momento deu-se quase uma década depois, quando, cursando o doutorado, como mencionei, pretendi fazer uma "antropologia da antropologia" com ênfase no caso brasileiro, e tendo França e Alemanha como os outros pontos do triângulo. ${ }^{6}$ Foi o momento de grande imersão na literatura brasileira de ciências sociais: tendo passado pela experiência acadêmica e intelectual nos Estados Unidos por cinco anos, precisava enfrentar um exercício de autorreflexão antes de voltar. O terceiro momento, então, se resume ao encontro na rua Nebraska, quando tive o privilégio de conversar sobretudo sobre seu trabalho de análise dos Tupinambá, e também ver seu famoso e enorme fichário. (Hoje tendemos a esquecer as condições de sua pesquisa, em uma época das fichas $3 \times 5$.) Ao reler sua obra por inteiro para me preparar para o encontro, impressionei-me com a dimensão extraordinária da sua pesquisa e análise do material seiscentista, que desconhecia até então, e perguntei-me por que eles não foram a semente da antropologia que vingou no Brasil. Finalmente, o quarto momento é o de uma carta que Florestan me mandou em resposta a dois textos que lhe enviei: minha tese de doutorado e um artigo que havia publicado sobre sua "antropologia esquecida". Essa carta, ao mesmo tempo dura e bela, só Florestan poderia escrever.?

$\mathrm{Na}$ tese, Florestan adquiriu um papel fundamental. Ao organizar o argumento central, no ano seguinte à nossa conversa, ele se revelou exemplar nas nossas ciências sociais. Sua biografia indicava dilemas e paradoxos que se tornaram, em vários sentidos, arquetípicos; nela ressaltava seu empenho intelectual intimamente vinculado ao institucional; sua trajetória apontava para um impasse que ora oscilava, ora combinava o caminho teórico-universal e o engajamento político; e, mais que tudo, sua carreira reforçava um padrão acadêmico marcado pela seriedade e pela honestidade intelectual. Assim, não por acaso, o primeiro capítulo da tese foi dedicado a um só autor, exatamente Florestan.

S\&A. Vocês estavam falando sobre a primeira fase do Florestan, sobre seus primeiros escritos. Até hoje é muito comum a divisão da sua obra em fases: científica, militante, antropológica, sociológica, uma fase antes e depois do golpe. É mesmo possível classificá-la em fases ou há um fio comum com modulações?

G.C. Modulações é uma boa palavra.

E.R.B. Eu acho que há um fio condutor nos temas que se tornam seu objeto de reflexão. O tempo todo ele faz uma pergunta: "como é que se explica um país capitalista que até se desenvolve num dado momento, mas cujo desenvolvimento é diferente, pois implica ao mesmo tempo exclusão, miséria etc.?" Isso vale para todas as fases do Florestan, me parece; até para o momento em que 
ele estava na Escola de Sociologia e Política. Em I 942 ele fez uma pesquisa em Sorocaba sobre João Camargo orientada por Roger Bastide e intitulada "Contribuição para o estudo de um líder carismático". ${ }^{8}$ Percebeu, então, que precisava aprender a fazer pesquisa de campo e foi estudar com Willems. Enquanto estava na Escola de Sociologia e Política, Florestan fez um trabalho fantástico, não publicado integralmente (ele alegou que a terceira parte precisava ser revista), sobre Mannheim político, que coloca este mesmo ponto: sociólogo, intelectual no Brasil tem o compromisso de pensar a situação brasileira. É essa a linha que reúne todas as fases, que são muito diferentes em termos de produção.

G.C. A Escola de Sociologia e Política guardava arquivos de trabalhos dos antigos estudantes, incluindo Florestan. Não sei em que pé está isso.

E.R.B. Eu olhei a pasta; nela havia uma prova que ele fez com Baldus, cuja questão era: disserte sobre as mudanças culturais no Brasil. Florestan responde mais ou menos assim: "há vários momentos importantes de mudança cultural do Brasil. O primeiro momento é o da crise do pacto colonial e da independência; o segundo momento..." E assim vai. Ele faz ali, e lembremos que ele estava no primeiro ano da Escola de Sociologia e Política, a construção histórica que fará depois para discutir a revolução burguesa. E Baldus risca a prova e dá zero para ele, porque se tratava da discussão sobre o que é cultura pela perspectiva da antropologia, mas Florestan já estava pensando o Brasil.

G.C. Mas eles se dão bem depois.

E.R.B. Sim, Florestan será seu orientando depois. Isso indica que Florestan achava que tinha muito a aprender com os outros. Esse sentido de reciprocidade mencionado pelo professor Gabriel estava presente ali. Qualquer aluno que tivesse tirado zero nunca mais falaria com o professor. Florestan deve ter refeito a disciplina... E mais, o livro Função social da guerra na sociedade tupinambá é dedicado aos professores Roger Bastide e Herbert Baldus...

G.C. Eu era péssimo aluno de ciências sociais; se histórico escolar importasse naquela época eu não estaria aqui falando com vocês. Uma professora que foi dura comigo, me deu nota dois em uma prova (não foi só ela a fazer isso), foi Maria Isaura Pereira de Queiroz. Lembro isso porque, mesmo sendo adversária de Florestan e com formação inteiramente diferente, ela foi muito íntegra com ele em momentos difíceis. Eles faziam parte de duas cadeiras diferentes - Sociologia I e II -, brigavam como cão e gato, mas quando ele foi aposentado e estava mal, Maria Isaura foi de grande dignidade e o procurou, não deixou que as desavenças interferissem.

S\&A. E como vocês veem a relação entre a sociologia e a antropologia na obra do Florestan Fernandes? Devem ser pensadas como fases ou podemos pensar como uma relação cognitiva constitutiva da sua perspectiva como um todo? 
Por exemplo, ele não vai levar uma discussão importante sobre cultura da antropologia para a sociologia?

M.P. Na época de formação de Florestan, sociologia era sinônimo do que hoje chamamos genericamente de ciências sociais. A sociologia era concebida em um estilo durkheimiano inclusivo - possivelmente vindo dos franceses e defendido por Fernando de Azevedo. Mas uma década depois, essa grande sociologia começou a se desmembrar no que hoje entendemos como as diversas "ciências sociais" (mas até hoje a gênese desse vínculo persiste em fóruns como a própria Anpocs). Nesse processo de desdobramento, as disciplinas se refundaram, foram redimensionadas, entraram em disputa por hegemonia e mais ou menos se acomodaram, reformulando muitas vezes os objetos próprios das disciplinas como anteriormente conhecidas.

Florestan estuda e começa a lecionar no ambiente dos anos 1940/1950 e, não por acaso, o primeiro curso que oferece é sobre Durkheim. É o momento "eclético", no dizer tanto de Florestan quanto de Antonio Candido, quando "se procurava combinar o trabalho intelectual profundo a um conhecimento das várias correntes de pensamento". ${ }^{9}$ Essa geração foi bombardeada por leituras de várias tendências. E Florestan era particularmente ávido por ler e aprender, como Elide e Gabriel destacaram.

Não espanta, então, que no artigo sobre a contribuição etnográfica dos cronistas, Florestan cite um conjunto invejável de antropólogos: além de Durkheim, Malinowski, Radcliffe-Brown, Ruth Benedict, Lowie, Murdock, Margaret Mead, Thurnwald, Métraux, Mauss e Bateson. O artigo a que me refiro foi inicialmente publicado em I 949 na Revista do Museu Paulista e reproduzido em I 975 como capítulo V de A investigação etnológica no Brasil e outros ensaios. É só quando, posteriormente, ele sente necessidade de atuar em "confronto com a sociedade", de tornar-se verdadeiramente um sociólogo, que essa formação básica vai-se particularizar a partir do estudo do negro. Embora Florestan tenha dito que se engajou na pesquisa "por acaso", há muito ele e Antonio Candido se preocupavam em "como fazer o leitor perceber que somos socialistas". A aspiração de fundir atividade política e atividade intelectual foi sempre uma preocupação e um desafio, vindos de sua formação acadêmica. Ele cita Durkheim, que já afirmava que, "se a sociologia não servisse para nada, não valia a pena".

E como, então, ficam os Tupinambá? Ficam como prova de respeitabilidade da ciência, para si e para a comunidade acadêmica no início de sua carreira. Os estudos dos Tupinambá, embora pouco lidos na época, "fizeram" seu autor. Florestan firmou-se institucionalmente e conseguiu atingir a liberdade para seguir adiante a fim de desenvolver uma sociologia interessada, crítica e militante.

Eu própria só li sobre os Tupinambá na época em que me preparava para entrevistá-lo. Fiquei impressionada, então, com a potência de sua análise, sua monumentalidade: por que haviam sido esquecidos? Por que ninguém lia esses livros? Por que não vendiam? Por que não os reeditavam? Por que Flores- 
tan, ele próprio, dizia que fora apenas seu período de aprendizado, a não ser repetido por seus alunos? E minhas perguntas sobre os Tupinambá, talvez inesperadas, foram bem-vindas. Grande parte da nossa conversa girou sobre sua pesquisa, seu fichário, a análise das fontes, chegando ele a comentar que essa pesquisa tivera efeitos posteriores inesperados. Por exemplo, frente à frustração de não conseguir que os participantes da pesquisa sobre o negro produzissem documentos escritos, como ele e Bastide haviam imaginado, lembrou-se das reuniões tribais na sociedade tupinambá e de reuniões análogas na África, sobre as quais havia lido. E ele então diz para Bastide: "Se não escrevem, falam. Temos que criar a situação de grupo em que eles falem”. Daí as reuniões inspiradas nos Tupinambá.

E.R.B. Concordo com Mariza, pois sociologia, naquele momento representava o conjunto das ciências sociais. Essa pergunta que você faz não é fácil, porque depende do que se entende por sociologia e antropologia. Como eu já disse, ele aprendeu com Willems sobre socialização, que, embora seja tema central para a sociologia, acabou, com o decorrer do tempo, ficando mais no âmbito da antropologia. E a perspectiva que enfatiza o processo de socialização é fundamental em A integração do negro na sociedade de classes. Como disse o professor Gabriel, Florestan leu e fazia seus alunos lerem todos os grandes autores brasileiros. Em Circuito fechado, ele faz uma crítica a autores brasileiros que considera muito respeitáveis - refere-se a Alberto Torres, Oliveira Vianna, Gilberto Freyre: eles estão centrados numa microssociologia que é extremamente importante, mas que não resiste se não estiver ao lado da macrossociologia. Florestan usa esses termos já muito mais tarde. Ele propunha uma aproximação entre as áreas e denominava etnometodologia, o que a alguns autores parece descoberta recente.... Ao buscar nos meus papéis vi que ele organizou um simpósio que se chamava Etnossociologia, no Congresso Americanista de I955; tenho, aliás, um trabalho que Antonio Candido apresentou nesse simpósio, o que mostra uma abertura para outras áreas.

M.P. Concordo com Elide quanto à ideia de uma etnossociologia, como definida por Baldus em I954, combinada a uma macrossociologia. Mas complemento trazendo à lembrança a própria fundação da USP como um momento sociogenético. A meu ver, Florestan é o produto-modelo dessa ideia de universidade, criada com o objetivo ambicioso de contribuir para representar o cérebro da nacionalidade e para desenvolver um projeto acadêmico e político para educar a elite nacional. A Faculdade de Filosofia da USP, que não pretendia formar filósofos, criou o ambiente propício para que se desenvolvesse uma certa atitude acadêmica inovadora, de que Gabriel e Elide podem falar melhor do que eu.

Florestan parece ter assumido o legado da USP de forma exemplar. Não como os professores da missão francesa pretendiam, preocupados que estavam em desenvolver nos estudantes a capacidade de adquirir e compreender ideias novas e clássicas. Não. Florestan respondeu a eles com a ambição de criar co- 
nhecimento de forma original e com o máximo de independência possível. É assim que entendo seu objetivo de substituir o símbolo "made in France" pelo "feito-no-Brasil"; de criar não uma "sociologia brasileira", mas uma "sociologia feita-no-Brasil". A diferença entre as duas é fundamental.

Entre a urgência dos problemas sociais e a necessidade de defender a respeitabilidade da ciência objetiva - o clássico paradoxo do Iluminismo -, Florestan lançou suas ferramentas. Para ele, o fato de viver, produzir e agir nas condições de desenvolvimento do capitalismo e de dependência significava que empréstimos externos poderiam sempre ser benéficos, se se mantivesse uma dimensão crítica e participante.

G.C. Acho que Elide matou a charada, não tenho nada mais a dizer a respeito.

E.R.B. Bem, você fez a primeira resenha sobre A integração do negro na sociedade de classes.

G.C. A primeira, é verdade. Acho que Baldus, que havia combinado com Florestan de publicá-la na Revista do Museu Paulista, que dirigia, não chegou a fazer isso, pelo menos eu nunca a vi. ${ }^{\text {10 }}$

E.R.B. É uma excelente resenha em que você também faz uma crítica a Florestan.

G.C. Só depois eu fui revê-la. Eram tempos muito curiosos. O Florestan era já uma figura proeminente, e eu apenas um estudante terminando a graduação, entrando na pós. Vocês têm que ver a petulância como o texto termina, algo do tipo "até que esse homem leva jeito". Se fosse outro que não Florestan eu me daria mal. Por outro lado, aquela resenha rendeu um enorme elogio do nosso querido Luiz Pereira: "Você conseguiu entender o autor melhor do que ele mesmo".

S\&A. Você percebeu já nessa primeira leitura a centralidade do tema da socialização?

G.C. Eu não cheguei a captar esse ponto como a Elide. O que estava lá e que chamou a atenção do Luiz era a ideia de que Florestan teve o achado extraordinário de pegar o grupo que tinha pior ponto de partida no processo todo - e eu tenho a impressão de que até hoje tem. É a perspectiva plebeia. A perspectiva plebeia se define em oposição à patrícia, senhorial. Nós temos essa distinção muito marcada. Quantos países têm a sorte do Brasil, de ter seus dois maiores talentos sociológicos da época, um pela perspectiva senhorial, outro pela perspectiva plebeia? Dois grandes nomes - Gilberto Freyre e Florestan Fernandes - que eram “irmãos-inimigos". Eles fecharam a interpretação, é fantástico. Quantas vezes Gilberto Freyre não gostaria de oferecer um licorzinho ao Florestan, e o faria com muito gosto. Para dar uma ideia de como essa questão é desconcertante, é só pensar no grande debate entre Florestan e Guerreiro Ramos, esses dois plebeus. Não havia polarização social/cultural nesse caso. 
Uma vez eu estava com um livro do Guerreiro Ramos que tinha na contracapa uma foto de Guerreiro, muito marcada com contraste, ele aparecia fortemente negro, e um rapaz que estava, como eu, esperando para ser atendido em algum local burocrático, viu o livro e, apresentando-se como candidato ao Instituto Rio Branco, comentou diante da foto: "não tenho referência desse homem, mas, evidentemente, ele é um ressentido".

Há alguns outros autores que ampliam a gama de análise da perspectiva plebeia. Na França também há um contraste fantasticamente bom a ser desenvolvido que é Bourdieu, o plebeu, e Touraine, o gentleman. Trata-se realmente de uma escolha ditada por um estilo e uma posição, porque só por essa perspectiva específica, a plebeia, o grupo com o pior ponto de partida é referência central na análise de um denso processo social. Brincando um pouco, poderia dizer que Florestan não precisou ler John Rawls para dizer: "se houver desigualdades, que seja a favor dos de menos".

S\&A. A perspectiva plebeia do Bourdieu, porém, parece bastante diferente da do Florestan.

G.C. Valeria a pena tentar fazer uma análise comparativa dos dois, renderia no mínimo um mestrado. Um, na França com formação filosófica, foi fazer trabalho de campo na Argélia colonial, iniciando uma trajetória que vai da etnologia a uma sociologia militante; o outro, no Brasil, com formação acadêmica fortemente marcada por impulsos autodidáticos, foi pesquisar povos ameríndios na sua condição original antes da ocupação europeia como início de uma trajetória que também conduziria à sociologia e à militância. A questão, claro, é que os modos de pensar, de construir a estratégia de pesquisa e de ser combativo são diferentes.

S\&A. Na conferência feita pelo professor Antonio Candido no centenário da Abolição na Universidade de São Paulo, ele chama a atenção para o fato de que a sociologia, nos anos de sua institucionalização, ao colocar no centro do interesse de pesquisa o trabalhador rural, o trabalhador urbano, o pescador, o pequeno proprietário, o escravo, acabou provocando uma verdadeira rotação ao mesmo tempo cognitiva e ética nas humanidades.

G.C. Tomando a comparação do Florestan e do Bourdieu, temos contextos até políticos que têm muito a ver. Por exemplo, Florestan enfatiza sua posição de socialista, o que no caso implicava um vínculo apenas muito difuso com o partido, que era um clubinho. Bourdieu não podia ir por esse caminho, porque na França, além do Partido Socialista, estava institucionalizado o poderoso Partido Comunista. O caminho do combate estava muito mais demarcado, institucionalmente, no caso do Bourdieu do que no caso do Florestan. Por outro lado, Florestan tinha que, por sua conta, fincar as balizas. 
S\&A. Podemos até dizer que essa perspectiva plebeia, ou o modo de incorporar uma experiência plebeia, é muito diferente nos dois autores. No caso de A integração do negro, Florestan tinha mesmo uma relação próxima com seus colaboradores de pesquisa, e consegue incorporar aquela perspectiva plebeia não só como objeto, mas como sujeito, de maneira quase horizontal. Essa já é uma diferença em relação ao Bourdieu: Florestan coloca a experiência do sujeito no centro da investigação.

E.R.B. A observação é pertinente. O próprio processo de coleta de dados para a pesquisa sobre questão racial da Unesco e também para A integração do negro mostra esse aspecto. Os diferentes grupos organizados e representativos dos negros foram consultados. Organizaram-se sessões de debate, com perguntas do público. Conta-se que às vezes havia I50 pessoas nessas sessões, que se realizavam no auditório da Biblioteca Mário de Andrade. Lembro que me despertou a atenção o fato de Bastide e Florestan chamarem como depoentes da pesquisa pessoas e/ou grupos com posições bastante diferenciadas politicamente: por exemplo, Arlindo Veiga dos Santos, que era monarquista, José Correia Leite e Raul Joviano do Amaral, os três fundadores da Frente Negra, associação que foi proibida em 1938, mas que discordavam quanto ao encaminhamento dos movimentos negros. Os dois últimos são citados por Florestan Fernandes como colaboradores na pesquisa na nota explicativa de A integração do negro. Essa facilidade de entrada em grupos relativamente fechados só poderia acontecer por meio de relações de conhecimento anteriores e familiaridade com esse mundo. Nesse mesmo texto ele fala de "uma simpatia profunda e de um desejo ardente de compreender os dilemas com que o 'negro' se defronta socialmente". Quanto à comparação com a trajetória de Bourdieu, concordo com Gabriel: são dois lugares e duas formas diferentes. Creio que na França "o campo" tem fronteiras institucionais bem definidas e demarcadas por direitos, o que não é o caso por aqui. Os temas de A integração do negro e também de A revolução burguesa no Brasil, embora não dedicados à questão da formação do campo, mostram exatamente os paradoxos presentes na sociedade brasileira em que a discriminação racial é um claro obstáculo à igualdade de condições no exercício da competição. Exemplo claro disso é a tardia entrada de Florestan nos estudos fundamentais. Essa é uma diferença brutal. Ele teve que obter apoio, conforme conta. Trabalhava como garçom. Servia à mesa e depois ficava no canto lendo. Conta-se que aquilo chamou a atenção dos professores da Escola Riachuelo que frequentavam o local, que começaram a conversar com ele, percebendo que era inteligentíssimo e absorvia aquelas coisas de forma...

G.C. Selvagem.

E.R.B. Selvagem, é verdade, mas profundamente inteligente. Foram esses professores que sugeriram que ele fizesse o curso de madureza e lhe arrumaram $\mathrm{o}$ 
emprego como vendedor de laboratório, com horário mais flexível. Começou a se adaptar: em várias entrevistas ele conta as dificuldades de viver entre dois mundos.

Mário Medeiros lembrou que, quando ele fala dos dois mundos, faz referência ao mito da caverna. Fala sobre quando estava no fundo do poço e da dificuldade de sair dali porque sabia que teria pela frente muitos obstáculos. Confessa que via a realidade a partir de um espectro simplista. Além da sensação de, ao tentar sair do poço, estar traindo aqueles que lá ficavam. E que, por afetividade, estes dificultavam a saída, para não o ver desgarrar-se do grupo e perdê-lo. Obviamente ele só podia ter consciência das desvantagens no mundo porque já as conhecia muito bem. Por exemplo, o trajeto de Gilberto Freyre foi diferente: a família da mãe tivera engenhos e perdera. A família do pai parece que não. O pai era professor de curso secundário do colégio americano batista, onde Gilberto Freyre e seu irmão Ulisses foram estudar, e posteriormente em Baylor, Universidade dos americanos batistas.

S\&A. Ele reconfigurou a versão sobre suas origens sociais.

E.R.B. E ele reconfigurou como se fosse de uma família aristocrática. Casou-se aos 40 anos com mulher de família rica e de alta posição social. Chegou a Oliveira Lima convidando-o como paraninfo em sua formatura de ginásio. Quando estava em Baylor trocou correspondência e foi visitá-lo. Depois foi para Columbia. Portanto, Gilberto Freyre montou a ideia de um pertencimento patrício, quando, na verdade, esse pertencimento foi mais ou menos construído. Lembro o texto de Darcy Ribeiro em que o chama de reacionário. Gilberto Freyre amava aquele texto, porque nele Darcy dizia mais ou menos o seguinte: "é um inglês nos trópicos, veste flanela no clima de Pernambuco, toma chá às cinco horas e é um reacionário, mas é o melhor intérprete do Brasil". Tinha orgulho daquele texto, afinal muito do que ele desejava estava naquela curta frase.

S\&A. Isso aparece no filme do Joaquim Pedro de Andrade sobre Gilberto Freyre, O mestre de Apipucos, que, aliás, era para ser visto junto com O poeta do Castelo, sobre Manuel Bandeira. Ali vemos o contraste com a humildade do cotidiano de Bandeira, que acorda, faz o cafezinho dele, desce para comprar o leite, compra o jornal.... Enquanto Gilberto Freyre aparece numa situação que é quase uma comédia de costumes, porque com ele está dona Madalena e um copeiro, que aparentemente tem até dificuldade de andar calçado, de mão enluvada para servir o chá. Ouve-se a voz de Gilberto Freyre ao fundo dizendo: "eu e minha senhora, ao cair da tarde, sentamos aqui na varanda para tomarmos chá".

E.R.B. Quando fui entrevistá-lo, numa tarde, ele me disse: "você quer tomar alguma coisa? Infelizmente eu não posso lhe oferecer chá, porque Madalena me convenceu que nós não temos mais criadagem para isso".

G.C. Ianni uma vez me falou: "Florestan é homem talhado a machado". Ele não foi polido. 
E.R.B. Gilberto Freyre era capaz de ser delicado, mas também de uma rudeza terrível. E o Florestan que parecia rude era também delicadíssimo.

M.P. Sim, Gabriel. Lembremos que a geração de Antonio Candido e Florestan chega depois dos ensaios histórico-sociológicos, de autores como Gilberto Freyre e da autorreflexão literária, isto é, da época em que o conhecimento precisava ser transmitido como literatura. Florestan queria quebrar essa tradição, queria desenvolver uma ciência positiva. Chego mesmo a pensar que seu estilo pesado, austero, sem qualquer concessão à linguagem poética era não apenas resultado de sua expressão espontânea, mas, também, proposital, para marcar uma linguagem "científica". Plebeia, crua, sem refinamento (embora, como pessoa, como vocês disseram, Florestan fosse respeitoso e doce).

S\&A. Elide já mencionou Willems, Bastide e Mannheim. Gostaríamos que vocês falassem sobre as principais referências intelectuais, ou os diálogos mais relevantes, para Florestan, nos diferentes momentos da trajetória dele.

E.R.B. Como o professor Gabriel disse, Florestan teve várias bibliotecas, então não há como saber precisamente.

G.C. Florestan tinha um modo muito peculiar de se relacionar intelectualmente. Uma vez um colega lhe falou: "você estava nos Estados Unidos, não conversou com [Amitai] Etzioni? Ele tem uma obra interessante". Ele respondeu: "eu conheço a obra dele, não preciso ficar conversando com ele". Se uma obra fazia sentido para ele, era incorporada. É difícil reconstruir a rede de relações intelectuais de Florestan porque ele nunca se preocupou com esse aspecto. Trata-se estritamente de absorção ou não. Mannheim entra, aliás, Mannheim tem peso impressionante no pensamento social brasileiro.

E.R.B. Ele mantinha correspondência com Merton.

G.C. Mas o Merton deu uma colher de chá para ele, hein? Puxa vida. "Não leio português, mas esse Florestan fez um trabalho....". ${ }^{\text {II }}$

E.R.B. Acho que o contato dos dois se deu através de Wright Mills. Wright Mills e Florestan tiveram um debate em I959.

G.C. Um debate que, dizem, foi muito duro, não é?

E.R.B. Sim, foi um debate em torno de uma fala de Wright Mills no Seminário Internacional "Resistências à mudança: fatores que impedem ou dificultam o desenvolvimento", organizado por Costa Pinto, no Centro Latino-Americano de Pesquisas em Ciências Sociais, no Rio de Janeiro, em outubro de I959. Em sua comunicação "Remarks on the Problem of Industrial Development", Mills pergunta se o projeto de desenvolvimento aspirado por alguns participantes latino-americanos - uma terceira via entre os modelos soviético e norte-america- 
no - poderia ser alcançado pela via democrática. Florestan e Octavio Ianni pedem que esclareça o que quer dizer. Florestan, entre outros pontos, discorda quanto à interpretação do fracasso das previsões de Marx sobre a duração do capitalismo. Infelizmente no texto dos Anais do congresso não constam a resposta de Mills e os debates correspondentes.

S\&A. Vocês também assinalaram, em relação a esse tópico, que Florestan tinha disposição para aprender, o que dificultava a reconstituição dessa sociabilidade intelectual, porque provavelmente todos fizeram parte dela. Porém, tendo em vista ainda a perspectiva plebeia, talvez a dificuldade com a sociabilidade intelectual se dê também porque ela envolvia um elemento cortesão, que pode ser mais difícil para uns do que para outros.

E.R.B. É possível perceber, mas não é tão patente o peso que os autores têm para ele.

G.C. Ele não estava interessado no intercâmbio cultural. A observação é bastante interessante, porque mostra uma espécie de polarização: ou era o aprendiz - e absorvia o que queria -, ou era o mestre. O resto do território ficava vazio. Não se esqueçam de que, quando Florestan entrou na USP, ela era uma pequena universidade de uns "quatrocentões".

S\&A. O Antonio Candido conta que as senhoras de sociedade iam assistir às aulas dele, ainda enchapeladas. Um ar de Collège de France.

E.R.B. Sabemos que os setores dirigentes interessados na modernização de São Paulo apoiaram realmente a implantação da USP. Roberto Simonsen, por exemplo, é um dos idealizadores da Escola de Sociologia e Política, e a Faculdade de Filosofia chegou a funcionar na mansão de Jorge Street. Ambos foram os idealizadores, em I928, da Ciesp, depois Federação das Indústrias do Estado de São Paulo.

S\&A. Podemos passar para o segundo bloco de questões. Se o lugar de Florestan Fernandes como clássico das ciências sociais brasileiras parece assegurado e até mesmo consensual, isso não garante, porém, necessariamente, o reconhecimento do potencial mais heurístico de sua obra. Muitas vezes, justamente porque um "clássico", Florestan tem sido tratado como parte de uma história do passado. Mas como podemos pensar suas contribuições teóricas hoje?

M.P. Para mim, não resta dúvida de que A organização social dos Tupinambá e A função social da guerra na sociedade tupinambá são clássicos, mesmo que, paradoxalmente, sejam clássicos que "não pegaram". Nenhum dos dois foi influente para as ciências sociais na época de sua publicação, embora o tema fosse de interesse inegável para a antropologia. Paradoxalmente também, só nas últimas três décadas foram "descobertos" e tornaram-se alvo de reflexão, inspiração ou controvérsia. Foi preciso pesquisa etnográfica entre grupos tupi para que os 
livros de Florestan viessem à tona como obras de interlocução - sinal inequívoco do mérito de obras clássicas.

Cientistas sociais da geração de Florestan tentaram explicar esse esquecimento: Antonio Candido notando que os Tupinambá não faziam parte das preocupações candentes da época, além de ser leitura pesada e exigente; Darcy Ribeiro vendo A organização social como um clássico que ia ficar, mas A função social da guerra como um desperdício da "potência florestânica", já que seu argumento poderia ter sido apresentado em um artigo de 30 páginas.

Hoje, porém, o quadro é diferente e vou tentar ser mais precisa. A antropologia feita no Brasil deve a Florestan duas grandes vertentes no estudo do tema indígena. Entre os anos I960 e I980, os estudos sobre o contato interétnico nasceram, sim, da obra de Florestan, mas não dos Tupinambá. Não é curioso? Foi na abordagem sobre as relações raciais proposta por Florestan que Roberto Cardoso de Oliveira, seu ex-aluno, buscou inspiração para propor o conceito de fricção interétnica - conceito construído como equivalente lógico à ideia de luta de classes. Em outras palavras, a "sociologia" de Florestan inspirou Roberto a refutar as ideias, então em voga, de mudança social (vinda dos ingleses) e de aculturação (defendida pelos norte-americanos) e olhar o contato entre índios e brancos em si, como totalidade - não é por acaso, então, a afinidade dos títulos de Roberto Cardoso, $\mathrm{O}$ índio no mundo dos brancos, e o de Florestan, O negro e o mundo dos brancos. Os estudos sobre contato interétnico expandiram-se e permanecem como orientação central em várias áreas no Brasil.

A segunda vertente toma corpo na década de I980, a partir do trabalho de campo de Eduardo Viveiros de Castro entre os Araweté, grupo tupi, e, agora sim, tendo como interlocutor mais contundente o Florestan de A função da guerra, livro considerado por Eduardo "uma das obras maiores da etnologia brasileira". Depois de 30 anos, finalmente os Tupinambá ressurgem para produzir, em Araweté. Os deuses canibais, uma das mais felizes interlocuções intelectuais no cenário da antropologia no Brasil. Interlocuções que, diga-se de passagem, são escassas no Brasil.

Mas Eduardo muda a ênfase da organização social, que percebe em Florestan, para focalizar a guerra como cosmologia, na qual a presença global dos mortos é central. Mais tarde, desenvolve, em parceria com Tânia Stolze Lima, a ideia de "perspectivismo", teoria que revisa as noções ocidentais de natureza e cultura ao propor que, no mundo indígena, a cultura pode ser constante, e a natureza, variável. Uma reviravolta na antropologia e, quiçá, no pensamento ocidental.

Desconheço qualquer menção ao pioneirismo de Florestan na análise de fontes históricas no contexto dos estudos mais recentes de Marshall Sahlins, por exemplo, sobre o encontro do capitão Cook com os havaianos no século XVIII. Mas as pesquisas de campo de etnólogos no Brasil que beberam dos dois livros clássicos sobre os Tupinambá são hoje consideradas, no exterior, entre as grandes contribuições teóricas da antropologia contemporânea. O diálogo 
com nomes renomados internacionalmente e sua incorporação nos debates atuais nos centros mundiais têm atribuído grande visibilidade a esses trabalhos. Sinuoso caminho, o desses magníficos Tupinambá.

G.C. Um componente brilhante do pensamento dele que talvez tenha inesperada atualidade tem a ver com as relações - que deveriam ser reconstruídas, mas nunca foram que eu saiba -, entre a sua posição eclética e as posições recentes que reivindicam a famosa interdisciplinaridade. O modo como ele desrespeitava as fronteiras entre escolas de pensamento, posições metodológicas, autores etc. constitui marca sua. Por uma razão muito simples: para fazer o trabalho que ele fazia, juntando o que ele juntava, tinha que ser um virtuoso, senão saía uma geleia geral. Ele criou - e que eu saiba, ninguém refletiu a respeito - um modo de diluir fronteiras ou de absorvê-las numa configuração maior e mais articulada, que pode ser relevante para pensar os limites e o potencial dessa busca atual de contribuições múltiplas de várias áreas e formas de pensar. Florestan poderia nos ajudar muito nesse sentido. Isso não significa, porém, que eu seja entusiasta do uso abusivo da famosa interdisciplinaridade, sobretudo porque esse tipo de coisa é feito na ponta da pesquisa, não no dia a dia. Ou melhor, nas pontas das pesquisas, em que nos é exigido entender como amarrá-las. Florestan estava na ponta das ciências sociais da sua época. Quando ele fazia aquele tipo de observação que fez para mim - "eu estava falando isso há I5 anos" -, parece até um rompante, mas fato é que ele tinha condições de realizar aquilo como os que naquele momento estavam fazendo aquelas reflexões teóricas. E ele o faria de um modo que, acredito, pode ser trazido à baila agora, muito mais, eu diria, do que as reflexões mais convencionais dele sobre funcionalismo. Ele não era - nem queria ser, apesar de todo seu esforço -, um intérprete de alta qualidade do Marx, por exemplo. Mas, se estamos preocupados com as aproximações, as interpenetrações e superações de fronteiras entre modos de pensar na pesquisa, na reflexão sociológica, desconfio que Florestan possa ajudar. E isso só pode ser feito por meio de uma análise interna das obras dele. Não há uma reflexão dele a esse respeito, nem para provocar a discussão. Isto é curioso: um homem que lia tudo, refletia o tempo todo, mas tinha um forte viés do substantivo, do ir lá e cavoucar, do empírico no sentido mais poderoso do termo. Tenho a impressão de que toda a reflexão metodológica da época dele era instrumental, mas talvez esteja exagerando.

S\&A. Achamos interessante a forma como você colocou a questão; fez lembrar Talcott Parsons, que era contemporâneo dele, fazia pesquisa de ponta na sua época e montou um Departamento de Relações Sociais, composto de antropólogos, cientistas políticos, psicólogos. O modo como Parsons pensa a interdisciplinaridade, porém, enfatiza um sentido de convergências, ao passo que Florestan ressalta que é preciso enfocar a multiplicidade, porque o objeto do sociólogo é prismático. 
E.R.B. Sobre essa ideia do prisma, como eu a vejo, Florestan está apontando que o que vemos é a refração da luz, pois a visão depende sempre do lugar em que estamos. É aquilo que falei no começo, sobre a grande questão: temos a possibilidade de desenvolvimento desse capitalismo, da modernidade, e temos, convivendo nesse cenário, a exclusão, a pobreza. Essa situação coloca problemas com ângulos diferentes daqueles com que se deparam os analistas das sociedades centrais. E, ao fazer essa pergunta, eu acho que ele diz: não existe resposta pronta para isso. No começo de A sociologia numa era de revolução social, ele afirma que o sociólogo brasileiro tem a função específica de perceber o arranjo das mudanças sociais. Em outros termos, é importante refletir sobre a qualidade das mudanças e seu papel na integração do sistema social. O sociólogo tem que ser capaz de responder por que, nos países periféricos, os setores dominantes fazem tanta questão de ter o domínio, o controle das mudanças sociais. É atualíssima essa pergunta, como bem sabemos; a resposta é que é difícil, pois as variáveis a comparar são inúmeras.

G.C. Há uma passagem do Florestan em Sociedade de classes e subdesenvolvimento que afirma que a racionalidade dos eventos sociais está inteiramente ligada ao campo em que eles estão enredados. Florestan não tinha nada a ver com Bourdieu, mas, embora não a conceitue, ele está trabalhando o tempo todo com a ideia de campo. Haveria convergência? Quero dizer com isso que há afinidades reais no interior de um certo modo de pensar que seria o do plebeu. Touraine não faria essa observação. Florestan se beneficiou de uma posição, digamos, paradoxalmente não provinciana, cosmopolita, do pensamento social que se construía no Brasil nessa época, quando a internacionalização era menor. Lia-se tudo, de todos os lugares, de todos os autores, de todas as tendências. Não se ficava confinado no ambiente norte-americano nem no francês, que era absolutamente fechado.

E.R.B. Essa temática de pensar as margens, a periferia, é muito atual. Florestan pergunta se, para a análise de uma sociedade sem as características das sociedades centrais, é válido usar os mesmos instrumentos, as mesmas categorias analíticas. Por exemplo, no plano de estudos para a pesquisa da Unesco, questiona a utilização do conceito de preconceito, cuja abrangência não dá conta da história da sociedade brasileira. Mostra, então, que, embora a existência do preconceito seja negada por vários grupos e/ou autores, ele se expressa concretamente em um comportamento discriminatório. Tal posição está clara no prefácio da primeira edição de A sociologia numa era de revolução social, quando afirma que o sociólogo brasileiro pode contribuir de forma criadora para ramos da teoria sociológica não cultivados com facilidade pelos seus colegas dos países desenvolvidos - trata-se de um texto de ig62.

S\&A. O elo mais frágil. 
E.R.B. Sim, o elo mais frágil atualmente passou a ser muito importante, sobretudo quando vemos os problemas colocados pelos imigrantes em vários países da Europa.

S\&A. Heloísa Buarque de Holanda tem um projeto muito importante chamado Universidade das Quebradas. Ela tem dito que a periferia já não diz "somos periféricos", e sim "somos contemporâneos". Ser contemporâneo, porém, quer dizer que eles não estão fora do sistema, e que o sistema é que mudou. Evidentemente é uma fala política.

E.R.B. Tem razão. Lembrei-me de um trabalho de Stéphane Beaud, sociólogo francês, e Younes Amrani, pseudônimo de um jovem bibliotecário da periferia de Lyon. ${ }^{12}$ Trata-se da correspondência eletrônica entre o filho de imigrantes marroquinos com o autor sobre seu livro anterior, que mostra a eliminação paulatina de grupos no processo educacional francês, o que atinge maiormente os habitantes da periferia das cidades francesas descendentes de imigrantes. A troca de e-mails deu origem a um livro interessante no qual se explicita a dignidade negada a quem vive na periferia. Younes fala sobre o sofrimento que o não reconhecimento cotidiano e a marginalização social trazem aos jovens franceses de origem magrebina. Mais ainda, sobre a desigualdade de condições de competição a que estão submetidos. Esse texto de 2005 me lembrou muito a forma pela qual se organiza a fala do Florestan, que mostra a condição assimétrica entre negros e brancos no Brasil em relação à ordem social competitiva. Sem dúvida A integração do negro é uma análise sobre os limites da democracia no Brasil e pode ser alinhado à atualidade do debate que põe em questão a concepção formal de justiça e de igualdade de condições sociais, políticas e culturais. Não esqueçamos que foi publicado em I965, e a tese defendida em I964. Além dessa ampla pesquisa, nos vários textos em que aborda a questão das mudanças sociais, adequados aos diferentes momentos da conjuntura sociopolítica brasileira, Florestan fala sobre a relação existente entre o controle do processo de mudança e o poder político. Trata-se de um controle sobre quem se vale das vantagens advindas dessas mudanças. Ao longo da história brasileira, aponta para acordos políticos firmados tendo como objetivo impedir que as opções pela mudança não alterassem os interesses das camadas tradicionalmente acostumadas à estabilidade e à ocultação dos conflitos sociais. Estas buscam regular os debates sobre distribuição da renda e da terra, sobre direitos e movimentos sociais, com o fim de preservar o status quo e impedir que medidas referentes a esses temas possam ampliar o acesso à ordem social competitiva. A atualidade da questão salta à vista: basta constatar o incômodo provocado pelas políticas sociais no Brasil que "ameaçam" promover essa abertura, como, por exemplo, cotas raciais nas universidades, bolsa família, criminalização da discriminação racial. Tais reações e seu resultado político escancaram as oposições presentes na definição do sentido da democracia. 
G.C. É verdade que o pensamento de Florestan nunca se concentrou na celebração das virtudes da democracia nem na mera exigência de que as instituições políticas devessem assumir feitio democrático. Nunca foi indiferente a isso, claro, mas sua perspectiva era outra. Aqui, talvez mais do que em qualquer outro lugar, ele se apresentava como defensor de uma concepção deveras (ele gostava desse termo) intransigente de democracia de classe. E esse qualificativo, de classe, ele levava muito a sério; tanto que nunca aceitou a ênfase, que se expandiu a partir dos anos I980, na "sociedade civil" no lugar da classe como referência básica. Para ele, democracia burguesa, representativa e minimalista, centrada em eleições periódicas universais e livres, com mandatos definidos e assegurados, era uma coisa, importante sem dúvida (foi com base nela que se tornou deputado); outra coisa era a democracia de raiz popular. Essa distinção é componente fundamental do pensamento de Florestan e está na base de sua concepção de "autocracia burguesa" como sombra sempre presente numa sociedade como a brasileira, marcada pelas dificuldades de realização histórica da "revolução burguesa". É que, para ele, essa modalidade de autocracia não representa pura e simplesmente o oposto da democracia, mas é, precisamente, sua sombra sempre presente em segundo plano, para emergir, com maior ou menor virulência, em situações de crise do poder burguês. Uma frase de Florestan em contexto informal exprime bem isso. Referindo-se às condições do Chile no governo Allende, ele comentou: "os chilenos vão acabar conhecendo o que é uma burguesia enfurecida". A frase, que se revelou premonitória, guarda profunda atualidade no Brasil neste momento, no qual a fúria burguesa contra políticas muito mais tímidas do que as tentadas por Allende, em especial o aumento contínuo e sistemático do salário mínimo, conduziu (junto com outros fatores, claro, não só internos) a sociedade brasileira a uma autocracia palidamente velada. Tudo isso até permite supor que Florestan pudesse ter simpatia pela advertência tão mal compreendida (um episódio no jornal Folha de S. Paulo revelou isso de maneira brutal) e, no entanto, de enorme atualidade feita na fase dos estudos de "transição democrática" em escala mundial nos anos I980. Nela, estudiosos latino-americanos, em especial o argentino Guillermo O’Donnell, falavam em "transição transada" no estilo brasileiro. Por esse caminho, preveniam eles, pode-se muito bem sair da "dictadura" para cair na "dictablanda". Fossem inteiramente profetas, poderiam ter avisado: pode-se sair do regime autoritário aberto conduzido pela força dos militares com os devidos apoios civis para mais à frente encontrar-se em situação autoritária oculta por véu de normalidade constitucional, conduzida por exatamente aquela instituição que antes protegia os cidadãos do uso discricionário do poder, o Judiciário. Autocracia menos visível, porém mais direta. O protetor torna-se executor sempre que lhe apraz, mediante recurso diretamente seu e não solicitado a ninguém, a violência policial. O que Florestan talvez não cogitasse nesse contexto seria o dito mineiro de que quando a esperteza é muita acaba comendo o esperto. 
Até porque isso mantém a política como domínio dos "espertos", que, segundo ele, conhecemos bem demais. De um modo ou outro, diria ele, a autocracia burguesa está presente. A ela opõe-se a autocracia popular (ele jamais usou esse termo, é abuso meu), que, no caso, seria exatamente a democracia.

M.P. Penso, assim, ser importante pensar no significado de Florestan não apenas na sua obra escrita, mas nas lições de sua trajetória intelectual e acadêmica. A meu ver, Florestan tornou-se o arquétipo de cientista social no Brasil ao propor uma ciência social rigorosa, com base em estritos padrões de excelência; esses seriam padrões universais que, contudo, respondem a condições específicas de produção - influências externas são, portanto, essenciais e benéficas se respondem às "exigências da situação". A ciência social, então, não deve ser cópia ou ilustração de teses de fora, tampouco deve pretender apresentar-se como uma ciência social "brasileira”, mas, sim, feita-no-Brasil. A autonomia progressiva nasceria, então, do diálogo que leva em conta a localização do cientista e seu compromisso social crítico.

Recebida 24/08/I7 | Aprovada I0/09/I7

André Botelho é professor do Departamento de Sociologia e do Programa de Pós-Graduação em Sociologia e Antropologia da UFRJ. Pesquisador do CNPq (PQ) e Cientista do Nosso Estado da FAPERJ, publicou, entre outros, Essencial Sociologia (2013). É Editor Responsável de Sociologia \& Antropologia.

Antonio Brasil Jr. é professor do Departamento de Sociologia e do Programa de Pós-Graduação em Sociologia e Antropologia da UFRJ. É autor de Passagens para a teoria sociológica: Florestan Fernandes e Gino Germani (2013).

Maurício Hoelz é pós-doutorando com bolsa PNPD/Capes pelo Programa de Pós-Graduação em Sociologia e Antropologia da UFRJ. É autor de A violência que nos une (no prelo) e Editor Executivo de Sociologia \& Antropologia. 


\section{NOTAS}

I Para um balanço sobre a questão ver Antonio Brasil Jr. (2013).

2 Ver Cohn (2005, 200Ia, 200Ib, I999, I987, I986), Bastos (2013, 2002a, 2002b, I998, I99I, I988, I987) e Peirano (I984, I98I).

3 Ver a respeito Botelho (2013).

4 "A análise funcionalista da guerra: possibilidades de aplicaçao à sociedade tupinambá; ensaio de análise crítica da contribuição etnográfica dos cronistas para o estudo sociológico da guerra entre populações aborígenes do Brasil quinhentista e seiscentista". Revista do Museu Paulista, São Paulo, v.3, p .7-I29, I949.

5 Todas as entrevistas podem ser encontradas em <http:// www.marizapeirano.com.br/entrevistas.htm>

6 A tese de doutorado está disponível em <http://www.marizapeirano.com.br/teses/the_anthropology_of_anthropology.htm >.

7 A carta pode ser lida em: < http://www.marizapeirano. com.br>.

8 A pesquisa foi incluída posteriormente tanto na primeira edição de Mudanças sociais no Brasil (I960) quanto em $O$ negro no mundo dos brancos (I972). [N.E.]

9 Florestan Fernandes em entrevista concedida a Mariza Peirano, disponível em <http://www.marizapeirano.com. br/entrevistas/florestan_fernandes.html>.

Io A resenha foi publicada na Revista Latinoamericana de Sociología, II/2, I966. [N.E.]

I I No "Post-scriptum bibliográfico" de Teoría y estructura sociales, publicado em I964 pelo Fondo de Cultura Económica com tradução de Florentino M. Torner, Merton observa: "Ensaio sobre o método de interpretação funcionalista em Sociologia, por Florestan Fernandes (1953), é uma monografia informativa e sistemática que recompensa uma leitura ainda que apressada e falível como a minha" (p. 93). [N. E.]

I2 Beaud, Stéphane \& Amrani, Younes. Pays de malheur! Un jeune de cité écrit à un sociologue. Paris: La Découverte, 2005. 


\section{REFERÊNCIAS BIBLIOGRÁFICAS}

Bastos, Elide Rugai. (2013). Gilberto Freyre e Florestan Fernandes: um debate sobre a democracia racial. In: Motta, Roberto \& Fernandes, Marcionila (orgs.). Gilberto Freyre: região, tradição, trópico e outras aproximações. Rio de Janeiro: Fundação Miguel de Cervantes, p. 262-278.

Bastos, Elide Rugai. (2002a). Pensamento social da escola sociológica paulista. In: Miceli, Sergio (org.). O que ler na ciência social brasileira: 1970-2002. São Paulo/Brasília: Sumaré/Anpocs, p. I83-230.

Bastos, Elide Rugai. (2002b). O jovem Florestan. Jornal de Resenhas/Folha de S. Paulo, São Paulo, p. 2.

Bastos, Elide Rugai. (I998). Florestan Fernandes e a construção das ciências sociais. In: Martinez, Paulo Henrique (org.). Florestan ou o sentido das coisas. São Paulo: Boitempo, p. I43-I56.

Bastos, Elide Rugai. (I99I). A questão social e a sociologia paulista. São Paulo em Perspectiva, 5/I, p. 3I-39.

Bastos, Elide Rugai. (I988). Um debate sobre o negro no Brasil. São Paulo em Perspectiva, I/5, p. 20-26.

Bastos, Elide Rugai. (1987). A questão racial e a revolução burguesa. In: D'Incao, Maria Angela (org.). O saber militante: ensaios sobre Florestan Fernandes. São Paulo: Paz e Terra, p. I4O-I5O.

Botelho, André. (2013). Essencial sociologia. São Paulo: Penguin/Companhia das Letras.

Brasil Jr., Antonio. (2013). Passagens para a teoria sociológica: Florestan Fernandes e Gino Germani. São Paulo: Hucitec.

Brasil Jr., Antonio \& Botelho, André. (2017). Florestan Fernandes para dimensionar a força do presente. In: Botelho, André \& Starling, Heloísa (orgs.). República e democracia: impasses do Brasil contemporâneo. Belo Horizonte: Ed. UFMG.

Calvino, Italo. (2004).Por que ler os clássicos? 2 ed. São Paulo: Companhia das Letras.

Cohn, Gabriel. (2005). Florestan Fernandes e o radicalismo plebeu em sociologia. Estudos Avançados, I9/55, p. 245-250.

Cohn, Gabriel. (2001a). A integração do negro na sociedade de classes. In: Mota, Lourenço Dantas (org.). Introdução ao Brasil: um banquete no trópico, v. 2. São Paulo: Ed. Senac. 
Cohn, Gabriel. (200Ib). O sábio e o funcionário. In: Falcão, Joaquim \& Araújo, Rosa Maria Barbosa de (orgs.). O imperador das ideias: Gilberto Freyre em questão. Rio de Janeiro: Fundação Roberto Marinho/Topbooks, p. 209-2I4.

Cohn, Gabriel. (I999). A revolução burguesa no Brasil. In: Mota, Lourenço Dantas (org.). Introdução ao Brasil: um banquete no trópico, v. I. São Paulo: Ed. Senac.

Cohn, Gabriel. (I987). O ecletismo bem temperado. In: D'Incao, Maria Angela (org.). O saber militante: ensaios sobre Florestan Fernandes. Rio de Janeiro: Paz e Terra, p. 48-53.

Cohn, Gabriel. (1986). Padrões e dilemas: o pensamento de Florestan Fernandes. In: Moraes, Reginaldo; Antunes, Ricardo \& Ferrante, Vera B. (orgs.). Inteligência brasileira. São Paulo: Brasiliense, p. I25-I48.

Elias, Nobert. (1987). The retreat of sociologists into the present. Theory, Culture and Society, 4/2, p. 223-247.

Peirano, Mariza. (1984). A antropologia esquecida de Florestan Fernandes: os Tupinambá. Anuário Antropológico, 82 , p. $15-49$.

Peirano, Mariza. (I98I). The Anthropology that did not take hold: Florestan Fernandes on the Tupinambá. In: The Anthropology of Anthropology: the Brazilian case. PhD Thesis. Harvard University. p. 43-72.

Santiago, Silviano. (1973). Latin American literature: the space in between. Buffalo: Council on International Studies, State University of New York at Buffalo (Special Studies, n. 48).

Villas Bôas, Glaucia. (2006). A recepção da sociologia alemã no Brasil. Rio de Janeiro: Topbooks. 
Palavras-chave

Florestan Fernandes; autocracia burguesa; ordem social competitiva; centro e periferia; sociologia brasileira.

Keywords

Florestan Fernandes; bourgeois autocracy; competitive social order; centre and periphery;

Brazilian sociology.

\section{FLORESTAN FERNANDES ENTRE DOIS MUNDOS:} ENTREVISTA COM ELIDE RUGAI BASTOS, GABRIEL COHN E MARIZA PEIRANO

\section{Resumo}

Nesta entrevista Elide Rugai Bastos, Gabriel Cohn e Mariza Peirano abordam aspectos da trajetória acadêmica e intelectual de Florestan Fernandes, discutindo especialmente a atualidade da sua obra, seus achados teóricos mais relevantes, bem como suas dimensões políticas e éticas. Assim, por exemplo, esses especialistas revisitam a capacidade de interpelação contemporânea de conceitos como autocracia burguesa, ordem social competitiva e periferia entre outros, bem como discutem os múltiplos relacionamentos entre sociologia e antropologia, história e teoria, centro e periferia, universidade e movimentos sociais, passado e presente na obra do cientista social paulista.

\section{FLORESTAN FERNANDES BETWEEN TWO WORLDS: INTERVIEW WITH ELIDE RUGAI BASTOS, GABRIEL COHN AND MARIZA PEIRANO}

\section{Abstract}

In this interview, Elide Rugai Bastos, Gabriel Cohn and Mariza Peirano address some of the main aspects of the academic and intellectual trajectory of Florestan Fernandes, particularly the current relevance of his work, its key theoretical findings and its political and ethical dimensions. The three specialists review, for example, the capacity of concepts like bourgeois autocracy, competitive social order and periphery to interrogate contemporary realities. They also discuss the multiple relationships between sociology and anthropology, history and theory, centre and periphery, universities and social movements, past and present in the social scientist's work. 